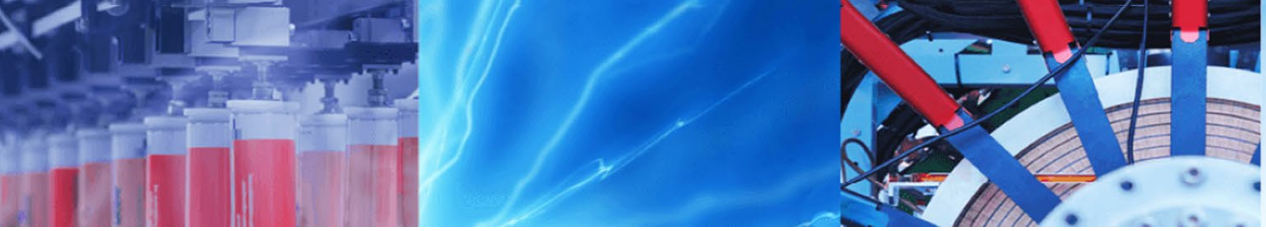

Review Paper

\title{
A new approach for the mandatory application of the thermal regulation of construction (RTCM) in the future moroccan buildings
}

\author{
B. M'lahfi $^{1}$ (D) D. Amegouz ${ }^{2} \cdot$ M. El Qandil ${ }^{1}$
}

Received: 21 October 2019 / Accepted: 19 August 2020 / Published online: 9 September 2020

(c) Springer Nature Switzerland AG 2020

\begin{abstract}
This study made it possible to retrace the major stages in the implementation of thermal regulations for buildings while placing them in their global and regional framework. This regulation, which was born following the crucial energy consumption experienced by the building sector and which has prompted countries to take regulatory steps to combat this scourge. Morocco is also committed to this approach by setting up the Moroccan Construction Thermal Regulation (RTCM), in order to guarantee energy efficient buildings. Following the comparison with the Thermal Building Regulations of Tunisia (RTBT), a country enjoying a comparable climatic and economic framework, our study also allowed us to underline the similarity of approaches in the two countries but also the delay experienced by Morocco in this implementation which fortunately is in the process of filling it by accelerating the procedures. Our work is in line with this perspective, by making it possible to highlight the steps taken in the establishment of this RTCM and those that remain to be developed, refined or adapted to the country context. In this sense, a broad consultation of stakeholders (decision-makers, prescribers and professionals) through a survey, allowed us to elucidate the reasons for the delay in the implementation of this RTCM, and the skepticism of both sides to its consideration favoring by far its voluntary aspect of its application. This consultation has especially enabled us to enrich this regulation for a better adaptability to the Moroccan context, ensuring at the same time a fairly flexible transition from a voluntary application to a compulsory application. In addition, we have reviewed the high performance insulation materials to be offered for both building envelopes and their structures. And for better performance, we have also proposed the integration of certain Moroccan standards in digital simulation tools for thermally insulating buildings and which will be developed in the next work.
\end{abstract}

Keywords Thermal regulation of construction Morocco-Tunisia - Thermal regulation of construction, mandatoryvoluntary $\cdot$ Green building $\cdot$ Insulating materials $\cdot$ Online survey

\section{Introduction}

The objective announced by the Moroccan Government is to achieve primary energy savings of around $12-15 \%$ by 2020 [1] through the implementation of an energy efficiency plan in the various economic sectors. Among the actions undertaken by the State in this context; the development of the Thermal Construction Regulation in Morocco (RTCM) which has as main objective, improving the thermal performance of buildings by reducing the need for heating and air conditioning. This can be achieved by improving the insulation of the building envelope as well as reducing the power of the heating and air conditioning equipment to be installed;

The RTCM constitutes a basic document serving as a technical prescription in the specifications of construction projects, extension or renovation of buildings. It is a tool to

B. M'lahfi, mlahfi.basma@gmail.com; D. Amegouz, amegouz@yahoo.fr; M. El Qandil, mostafelquandil@yahoo.fr| ${ }^{1}$ LERDD, FS- Université Sidi Mohamed Ben Abdelah, Fès, Morocco. ${ }^{2}$ LPEDD, EST- Université Sidi Mohamed Ben Abdelah, Fès, Morocco. 
help the thermal and energy optimization of the building envelope during the design phase.

Compliance with the RTCM requirements in the housing sector makes it possible to achieve final energy savings of around $22 \mathrm{kWh} / \mathrm{m}^{2} /$ year and a significant reduction in $\mathrm{CO}_{2}$ gas emissions [1-3], variable according to climatic zoning. Compared to the usual energy bill of the final consumer, these savings generate substantial gains estimated on average at $18 \mathrm{DH} / \mathrm{m}^{2} /$ year [1], compared to the usual energy bill of the end consumer.

In addition, the effective non-application of this regulation in buildings constructed after its appearance depends on several obstacles related mainly to the non-availability of a strategic plan and appropriate communication tools for the mobilization and awareness of stakeholders, including administrations, companies, professionals and the general public to energy efficiency measures in buildings.

This led us, in this article, to dissect the approach followed by the State in order to make the RTCM a regulatory device applied obligatorily and strictly in the buildings of tomorrow. Furthermore, this article is structured as follows:

- First of all, a presentation of the energy consumption which occupies the building sector in the world, the region south of the Mediterranean and Morocco;

- Subsequently, a review on the application of thermal construction regulations in the world and in the countries of the southern Mediterranean;

- After, a presentation of the research methodology which firstly contains a comparison of the requirements of the thermal regulations of building in two neighboring countries characterized by a climatic and economic rapprochement namely Morocco and Tunisia and subsequently, a survey which was launched online among stakeholders in the building sector in order to find out the cause which prevents a compulsory application of this regulation in new constructions;

- Then after, the presentation of the results and discussion of the feedback received from the various parties questioned;

- Finally a glimpse of the prospect of the next job.

\section{Energy consumption in the building sector}

The energy consumption of buildings forms a large part of global energy consumption. The construction sector consumes up to $40 \%$ of all energy and contributes up to $30 \%$ of annual global greenhouse gas emissions [4]. This causes real environmental nuisances such as global warming, air pollution and acid rain [5].
Energy consumption in the tertiary sector is around $70-300 \mathrm{kWh} / \mathrm{m}^{2} /$ year, which is $10-20$ times higher than that in the residential sector [6]. Hence the future concerns about methods of supply, depletion of energy resources and serious environmental impacts [7]. Furthermore, the overall contribution of residential and tertiary buildings to energy consumption has regularly increased, reaching values between $20 \%$ and $40 \%$ in developed and developing countries $[8,9]$.

On the other hand, the growth of the population, the improvement of the standard of living and the means of comfort as well as the prolongation of the time spent inside the building, will lead to a continuation of the energy demand worldwide. For this reason, energy efficiency in buildings is today a primary objective of energy policy at regional, national and international levels $[7,8]$.

\subsection{At the world level}

The results of statistics carried out in 2010 at global level on energy consumption, have shown that the building sector alone accounts for around $28 \%$ of final energy consumption and contributes about one-third of the emissions of $\mathrm{CO} 2$ [1], as shown in Fig. 1:

In addition, and in view of the high energy demand in future years, energy consumption may increase by $70 \%$ between the period 2006 to 2030 in growing developing countries such as China and India [10].

The expected increases for Central America, South America and the Middle East are approximately 50\%.

In the case of Africa, the energy consumption resulting from the same period is estimated at $50 \%$. However, a smaller forecast increases of around $25 \%$ for the developing countries of Europe and Eurasia [10].

\subsection{In the southern Mediterranean region}

The southern Mediterranean region is no exception to this observation since, on average, the building sector

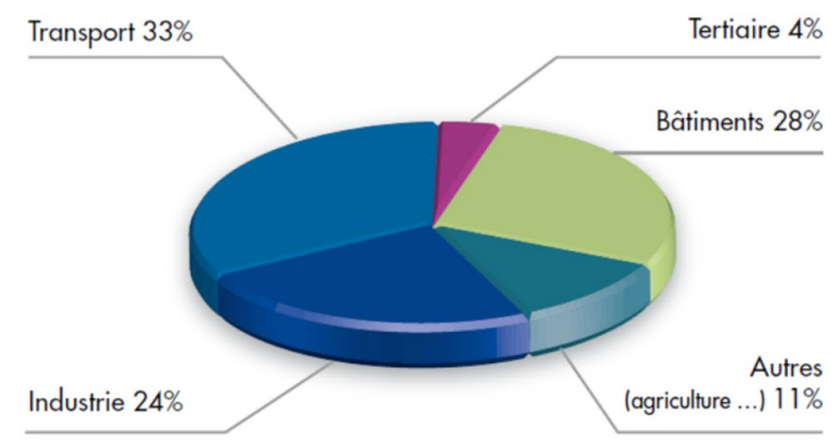

Fig. 1 World Building Sector Final Energy Consumption in 2010 [1] 
represents around $38 \%$ of the energy consumed (this percentage varies between $27 \%$ and $65 \%$ depending on the country). Compared to other industries, it represents the largest source of economy and is often around $40 \%$ in most countries of the region [1].

\subsection{In Morocco}

In Morocco, building is the second energy consuming sector after transport with a share of $25 \%$ of the country's total energy consumption, of which $18 \%$ is reserved for residential and the rest for the tertiary sector as shown in Fig. 2. This energy consumption, due to various sources, generates an increase in the release of $\mathrm{CO} 2$ gas and subsequently an imbalance in our ecosystem [3].

This energy consumption is expected to increase rapidly in the coming years for two reasons:

- The noticeable increase in the household equipment rate in household appliances due to the improvement in the standard of living and the lower prices of these appliances (heating, air conditioning, water heating, refrigeration, etc.).

- The significant evolution of the building stock due to the major programs: Plan Azur for the hotel industry, emergency program for national education, program of 150,000 housing units a year, hospital rehabilitation program, etc.

\section{Thermal regulations in the building sector}

The rapid growth in energy consumption worldwide has raised concerns to remedy this scourge. Several countries are therefore committed to the development of energy regulations and standards aimed at reducing the energy consumption of buildings.

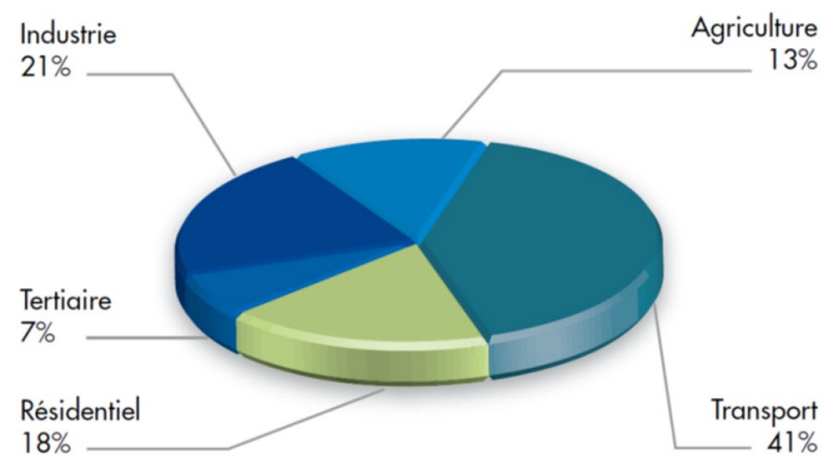

Fig. 2 Structure of consumption by sector [1]
The energy regulation of buildings aims to reduce the energy consumption of the building and its systems such as heating or air conditioning [11]. It is one of the most frequently used instruments for improving the energy efficiency of the building envelope and ensuring the safety and health of those inside. [12]

Thermal regulation plays an essential role in specifying how buildings should be constructed and the steps to follow to comply with thermal insulation standards by setting minimum requirements for energy efficient design and construction. [13]

\subsection{The application of the thermal regulation of construction in the world}

Several research studies have been directed towards identifying the application of thermal building regulations in the countries covered by their studies. Among this research, we find that carried out by the World Energy Council, which launched a survey of 63 countries and it demonstrated the existence of mandatory standards for new buildings in all European countries [14].

As well, work by author Janda [5] has identified the global status of energy standards for buildings, focusing more on developed countries. His work was based on a survey sent to 81 countries. The results showed that 61 countries apply existing mandatory standards, while 11 countries apply such standards on a voluntary basis and that 9 countries have no standards.

Most European countries have established mandatory energy standards for new housing and service buildings; while almost half of the countries in Asia and America have imposed mandatory standards and the other half have imposed these standards in optional way [15].

In another study (Joseph et al. [13]), based on an online survey of 145 contacts from governments, research organizations and professionals from 95 countries, this study consisted of collecting detailed information on regulations energy consumption of buildings and its degree of control and application. This study showed that Singapore and the Philippines were the first to introduce mandatory or voluntary standards for commercial buildings, followed by Algeria, Malaysia, Egypt and Syria. In most countries, these standards are applied for residential dwellings and service buildings, except in Africa and in some Asian countries, the standards most often apply only to non-residential buildings [13].

This same study could also classify the countries which have a thermal regulation of the compulsory, voluntary, mixed and nonregulatory construction. The classification in Fig. 3 shows the results found: 


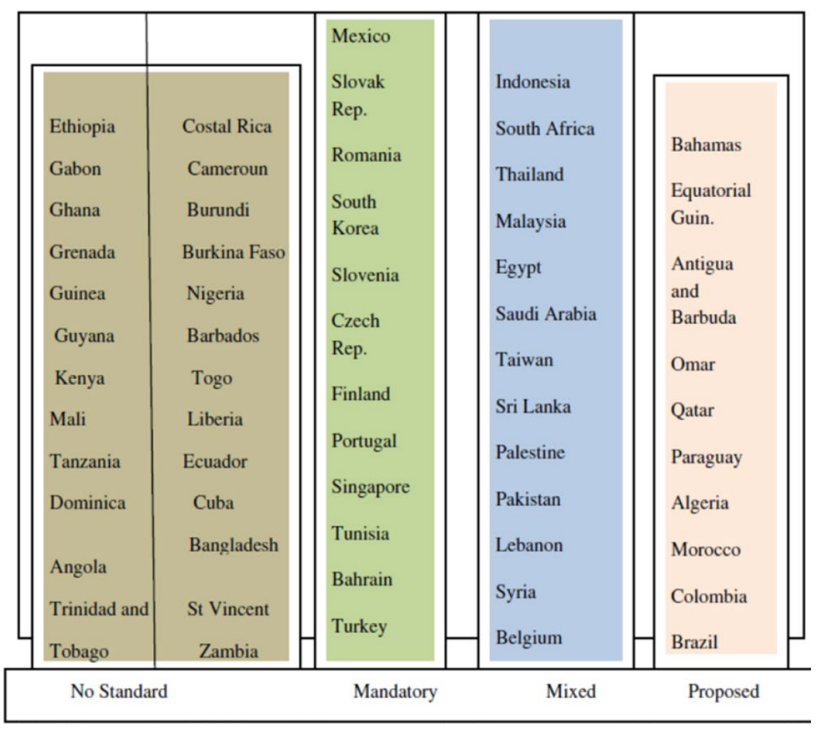

Fig. 3 Status of Building Energy Standards development and adoption in 60 developing countries (emerging and graduated/NIC), 2010 [13]

\subsection{The application of thermal construction regulations in the southern Mediterranean countries}

Similarly for the southern Mediterranean countries, most of these have adopted regulatory or normative measures for energy efficiency in buildings, as shown in Table 1: [1]

Developing countries are faced with various obstacles that hinder the proper application of building thermal standards and regulations. These obstacles are of several kinds; in particular, level of economic development, compliance and application.

On the other hand, we note from Table 1 that for certain countries, such as Tunisia and Turkey, the application of thermal regulation is compulsory, this encourages us to dig to find out the efforts made by the governments of these countries to allow compulsory application of this regulatory system.

\section{Research methodology}

Although the word "Regulation" means all the normative, legal and regulatory provisions making it possible to guide the operation of a system to be applied and to comply in a compulsory manner with the requirements imposed, however, the aforementioned studies distinguish countries, like Morocco, where thermal regulation of construction is proposed and its application remains voluntary, while other countries, like Tunisia, the application of this regulation is compulsory.

This means, that the regulatory provisions imposed for the systematic application of the RTCM in Morocco are moderately lightened or even unlocked, which led us to seek the real cause behind recent constructions which did not apply this regulation.

To do this, we were led in our research methodology, first, to make a comparison between the regulatory provisions of two neighboring Mediterranean countries, Morocco and Tunisia, characterized by a climatic rapprochement, in order to identify, on the one hand, the actions and practices that have led Tunisia to the compulsory application of this regulation. On the other hand, the obstacles to be overcome by the Moroccan government and the decision-makers to achieve it.

The input elements of our comparative study will be both the legislative and regulatory texts of the two "Morocco-Tunisia" countries as well as the results of the study carried out by the Moroccan Agency for Energy Efficiency (AMEE) and the National Agency for Energy
Table 1 Thermal Regulation in Southern Mediterranean Countries

\begin{tabular}{ll}
\hline Country & State of regulation \\
\hline Jordan & Thermal insulation standard in 1990 \\
& EE code in mandatory buildings (in the process of being adopted) \\
Lebanon & Thermal insulation standard in 2005, revised in 2010 \\
Syria & EE code in mandatory buildings \\
Turkey & Thermal insulation standard in 2000 \\
& Mandatory standard \\
Algeria & Regulatory Technical Document (RTD) in 1996 \\
& Mandatory since 2000 \\
Tunisia & Mandatory thermal regulation for offices in 2008 \\
& Mandatory thermal regulation for residential collective in 2009 \\
Egypt & Mandatory thermal insulation standard in 1998 \\
& EE code in buildings for residential compulsory in 2003 \\
& Code of EE in buildings for voluntary tertiary sector in 2005 \\
\hline
\end{tabular}


Management (ANME) in Tunisia aimed at strengthening the application of the Thermal Regulation of Moroccan Construction (RTCM) and the Thermal Regulation of Buildings in Tunisia (RTBT).

A broad consultation of stakeholders (decisionmakers, prescribers and professionals) through a questionnaire, will allow us to elucidate the reasons for the delay in the implementation of this RTCM, and the skepticism of each other towards it, but above all enrich this regulation for better adaptability to the Moroccan context.

Before presenting the comparative data, we will briefly present the two energy regulations of the two countries.

\subsection{The moroccan construction thermal regulation (RTCM) and its requirements}

The Moroccan Thermal Construction Regulation (RTCM) entered into force in November 2015, but its application is still voluntary. It initially applies only to new buildings and gives priority to the urban sector since energy consumption in rural areas is generally low. In addition, the RTCM covers the housing sector and tertiary buildings [1].

In the habitat the regulation targets all socio-economic categories of buildings, namely:

- Economic;

- Standing.

For the tertiary sector, four segments are particularly covered:

- The hotels;

- Administrative buildings (offices);

- Buildings of education and higher education;

- Hospitals.

For a better application of this regulation, the Moroccan territory has been subdivided into homogeneous climatic zones based on the analysis of climatic data recorded by 37 meteorological stations over the period of 1999-2008 (10 years). The construction of the zones was carried out according to the criterion of the number of winter degree days and the number of summer day's degrees $[1,16]$.

Two types of zoning were established by the National Meteorology Directorate (DMN) $[1,16]$ :

- Zoning based on heating degree days at $18^{\circ} \mathrm{C}$;

- Zoning based on cooling degree days at $21^{\circ} \mathrm{C}$.

The climate zoning works were carried out in close coordination between the DMN and AMEE, with the support of international expertise [1].
Table 2 Climate zones [2]

\begin{tabular}{ll}
\hline Zone 1 & Agadir \\
\hline Zone 2 & Tanger \\
Zone 3 & Fez \\
Zone 4 & Ifrane \\
Zone 5 & Marrakech \\
Zone 6 & Errachidia \\
\hline
\end{tabular}

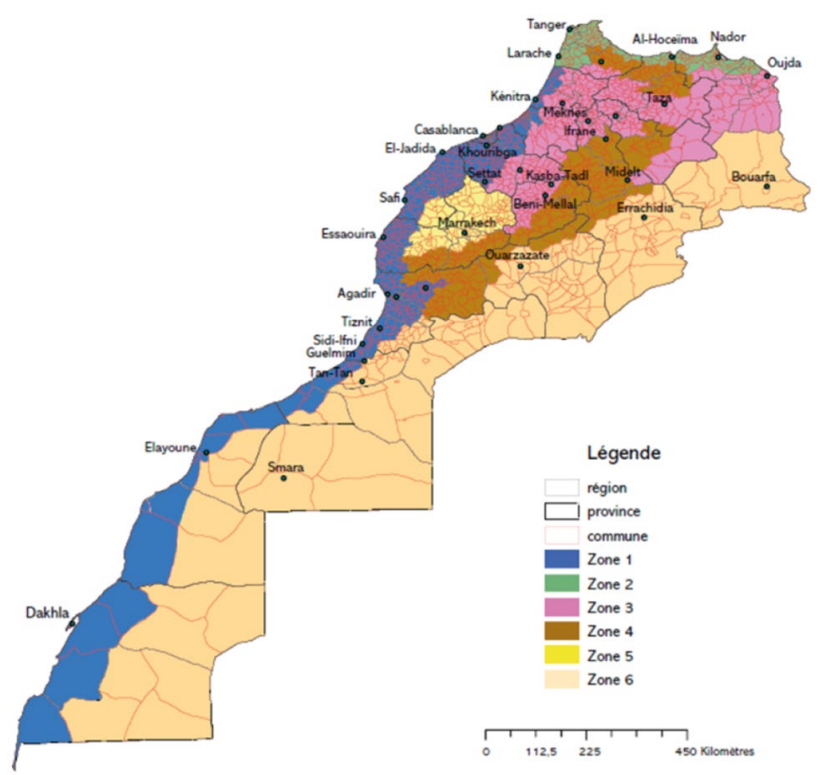

Fig. 4 Morocco's climate zoning adapted to Morocco's Construction Thermal Regulation [2]

The 6 climate zones are listed in Table 2 and the final zonation map includes the six climate zones shown in Fig. 4 [2].

The thermal regulation of construction in Morocco targets two sectors, residential and tertiary. The requirements of the first sector are the same for the different socio-economic categories of the buildings, they differ only from one climatic zone to another by fixing for each zone the minimum technical specifications, namely the rate of the bay windows, the minimum resistance of the floors on the ground, the solar factor of glazing and the thermal transmission coefficient of exposed roofs, external walls and glazings $[1,2]$.

On the other hand, in the tertiary sector thermal regulation specifically targets the four main branches of the tertiary sector, namely $[1,2]$ :

- Administrative buildings;

- Schools;

- Hospital buildings;

- Hotels. 
As for the residential sector, the technical specifications of the regulation for the tertiary sector and its impacts are determined for each of the branches and each of the zones, namely, the rate of the bay windows, the minimum resistance of the floors on the ground, the solar factor of the glazings and the thermal transmittance of exposed roofs, exterior walls and glazing [1, 2].

\subsection{The thermal regulation of buildings in Tunisia (RTBT) and its requirements}

The process of developing thermal regulation for buildings in Tunisia (RTBT) began with the phase of gathering climate data throughout the Tunisian territory. This work was piloted by the National Agency for Energy Management (ANME) and the National Institute of Meteorology (INM), it made it possible to establish a climatic zoning by geographical division. This has given rise to two categories of zoning: a regulatory zoning and another known as recommended.

The regulatory zoning distinguishes 3 climatic zones, namely: ZT1 which contains the coast going from the governorate of Bizerte to that of Gabès. The ZT2 which extends over the North and the Offshore Center of the governorate of Jendouba to the governorate of Gafsa. The ZT3 extends over the governorates of Tozeur, Kébili and Tataouine. [17]

In addition, the recommended zoning has made it possible to define 10 climatic regions of optimal relevance taking into account detailed climatic, administrative and socio-economic considerations (method of construction, tenure, etc.). This zoning mode is used, among other things, for the design and optimal sizing of heating and air conditioning equipment as well as for the thermal optimization of construction. [17]

Several ministerial decrees are promulgated to accompany these regulations aimed at fixing the minimum technical specifications for the saving of energy consumption, both for construction and extension projects for residential buildings and for construction and extension projects. office buildings. The other types of buildings (hospitals, hotels and shopping centers) are gradually promulgated.

And in order to better support the thermal regulation of new buildings, a Thermal Performance Label system by type of building has been introduced in regulatory texts, based on the annual energy needs related to thermal comfort (BECTh). Table 3 presents the label classes for new collective residential buildings:

The support of the Tunisian government for the establishment and application of RTBT was also supported by the subsidy of the following actions:

- Energy audit, program contracts and prior consultation;

- Cogeneration;
Table 3 The label classes for new collective residential buildings [17]

\begin{tabular}{ll}
\hline $\begin{array}{l}\text { Building thermal performance } \\
\text { classes }\end{array}$ & $\begin{array}{l}\text { Annual specific energy } \\
\text { requirements (BECTh) in kWh/ } \\
\mathrm{m}^{2} \text { year }\end{array}$ \\
\hline Classe 1 & BECTh $\leq 36$ \\
Classe 2 & $36<$ BECTh $\leq 41$ \\
Classe 3 & $41<$ BECTh $\leq 46$ \\
Classe 4 & $46<$ BECTh $\leq 51$ \\
Classe 5 & $51<$ BECTh $\leq 60$ \\
Classe 6 & $60<$ BECTh $\leq 72$ \\
Classe 7 & $72<$ BECTh $\leq 87$ \\
Classe 8 & $\mathrm{BECTh}>87$ \\
\hline
\end{tabular}

- Installation of benches for the diagnosis of vehicle engines;

- The use of energy efficient equipment in public lighting;

- Heating of water through the use of solar energy in homes and private businesses;

- The production of electricity from renewable energies;

- The substitution of energy by natural gas in the industrial sector, the residential sector and the collective public transport sector and any other operation aimed at controlling energy [17].

\subsection{Comparative study of the regulatory requirements of Morocco and Tunisia with regard to the energy performance of buildings}

In order to have a clearer visibility on the actions undertaken by the two countries in order to encourage the application of the thermal regulation of construction by the various stakeholders, this part is established in the form of a table (Table 4) summarizing the different comparative axes;

We see from the comparison table, that the two countries have started the same strategy to promote the application of their regulations and the same requirements are almost imposed by the two regulations, namely:

- The laws and regulations applicable in the matter;

- The creation of a national body to promote this strategy;

- The same enforcement target;

- The division of the country into climatic zoning, while fixing the technical specifications for each zone;

- The availability of national software to verify compliance with regulations;

- The obligation to carry out an energy audit; 


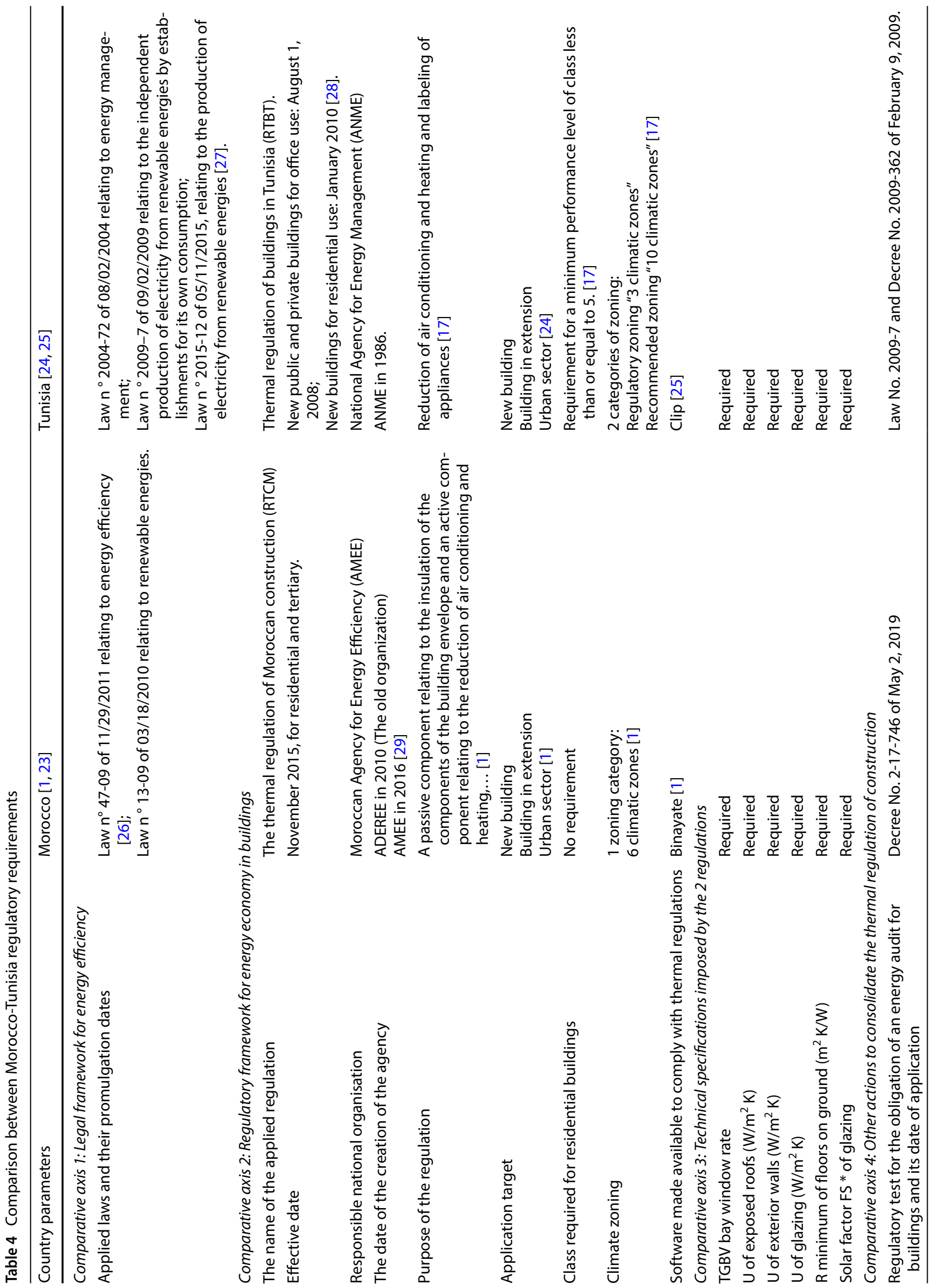




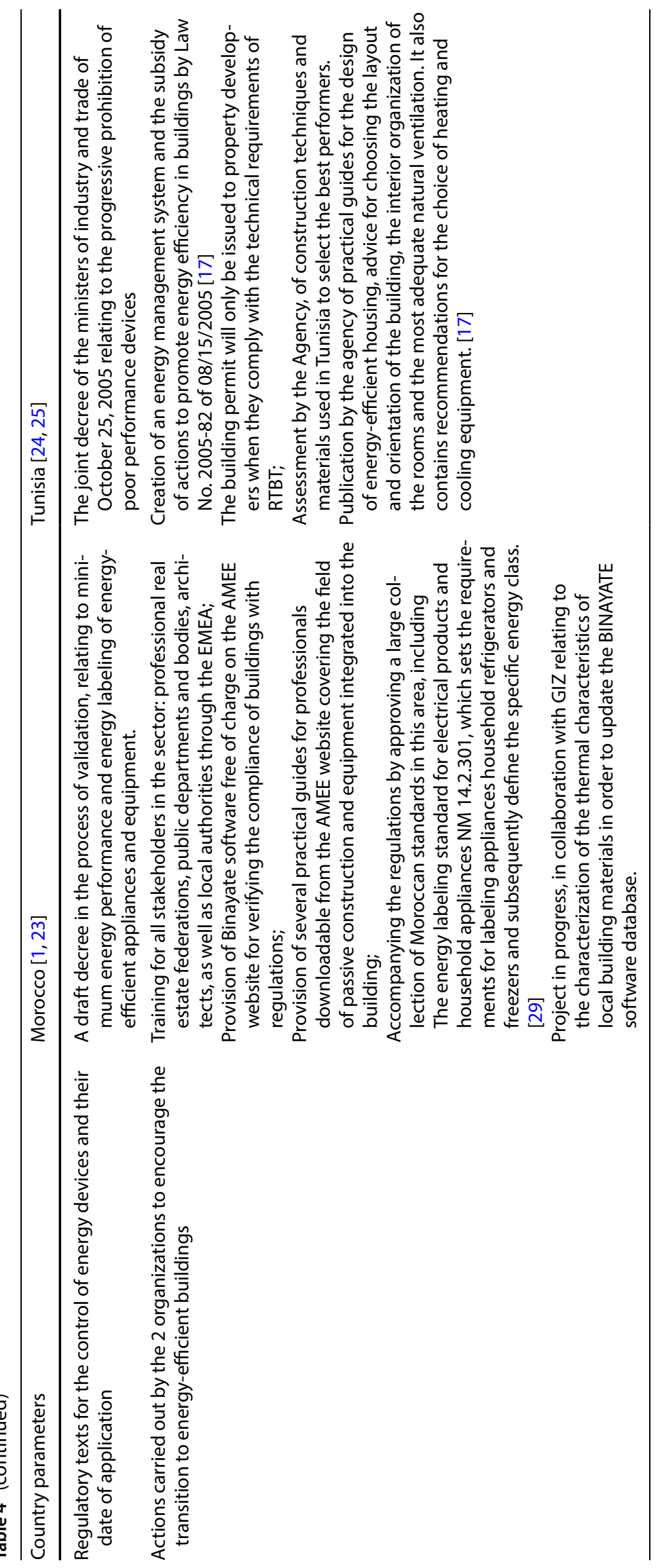

SN Applied Sciences

A SPRINGER NATURE journal 
- The availability of other means for the popularization of this regulation with interested parties, namely: guides, training, and adoption of international standards to support the application of all the requirements of the regulations...

However, we note a lag of up to 6 years both for the date of application of the law on energy efficiency as for the dates of application of the RTCM and RTBT as well as for the dates of creation of organizations respective national authorities in charge of these regulations.

We also note that Tunisia has already anticipated the labelling of high-performance appliances and high-performance constructions by assigning building thermal performance classes. In addition, Tunisia also anticipated the obligation of the energy audit by comparing it to Morocco, and it also anticipated the homologation of the law requiring the prohibition of energy-consuming devices, unlike Morocco which is still in the phase of confirmation.

In fact, in the case of Tunisia, the regulations were drawn up according to a global process based on broad consultation with all the stakeholders and associated with support and capacity building programs for designers, operators and suppliers of insulation materials.

In general, the feedback from this country shows the importance of the quality of the process of drafting the regulation as a key factor in its effective applicability.

However, with the present process launched in Morocco, the country is on the way to make up for the delay compared to other countries which have implemented compulsory thermal building regulations.

As well, thanks to the new strategic vision of Morocco in terms of energy and the effective involvement of all the actors concerned, including the promulgation of legal and normative texts accompanying the implementation of this regulation, Morocco will be able to catch up comfortably for the next 3 years, the existing gap in comparison with other countries where the application of their thermal regulation is compulsory.

\subsection{Survey of stakeholders in the construction sector in Morocco}

Despite the efforts made by the Moroccan government since its launch in November 2015, the application of the RTCM in our constructions is still timid, to even negligible.

From this observation, we were led to measure the real cause behind this delay in integration and the constraints that must be overcome, using a questionnaire that we sent by email to specifiers and decision-makers in the building sector, in order to first analyze the degree of their knowledge and involvement in this regulatory process and also to find out their recommendations and proposals for deducing a tangible action plan capable of making the application of this regulation compulsory and fluid with all stakeholders.

The survey involves a sample of architects, design offices, administrations and property developers, from which we received a return of 85 responses/ 120 requests sent. This questionnaire was developed using Google forms and was sent to the persons concerned in the form of the following link: https://forms.gle/8Xh4zCzbdmzgjgv c7

The construction of our questionnaire was based on the following criteria:

- The city of location;

- Measuring knowledge of the RTCM;

- The measurement of the application of RTCM in studies, prescriptions and current constructions. If not, the reason preventing it from doing so;

- Recommendations to popularize the benefit regulation;

- Identify if its application should be compulsory or voluntary;

- Discern if the standards related to energy efficiency in buildings are used in the specifications;

- Know if there are thermal simulation software that are used in the studies;

- The desire to integrate thermal simulation tools into the working software of specifiers;

- The desire to certify buildings with energy labels after the application of the RTCM in the study and design phase.

\section{Results and discussions}

Building sector decision-makers are most concerned with applying the RTCM in future constructions, whether it be specifiers such as architects, engineers or design offices, whose role is to prescribe the technical specifications of this regulation in the specifications and specifications, or the administrations which have a bilateral role in the prescription and execution, or even the property developers who must execute the prescribed recommendations and apply them in accordance;

The feedback received from architects was the majority in the survey that we launched online and it represents $74.4 \%$ of founded feedback, since they are considered the stakeholders most involved in the application of the RTCM, such as shows the Fig. 5 .

We also note following the analysis of the results of this survey in the graph below (Fig. 6), that the returns received more or less represent the 6 climatic zones delimited by the regulation; 

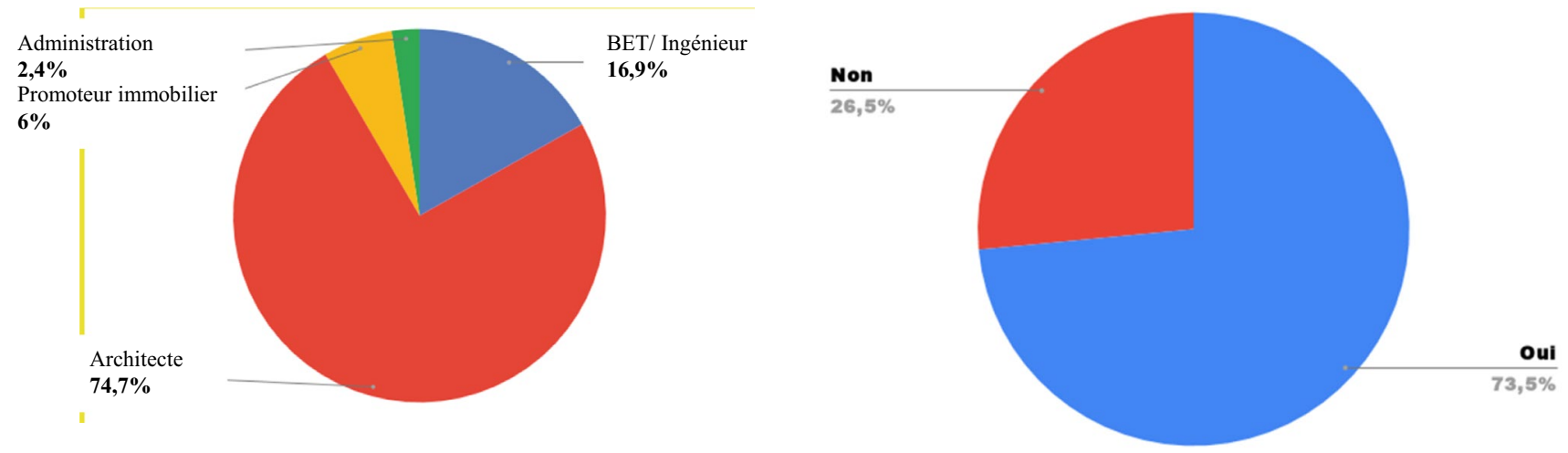

Fig. 5 Distribution of founded returns by stakeholders

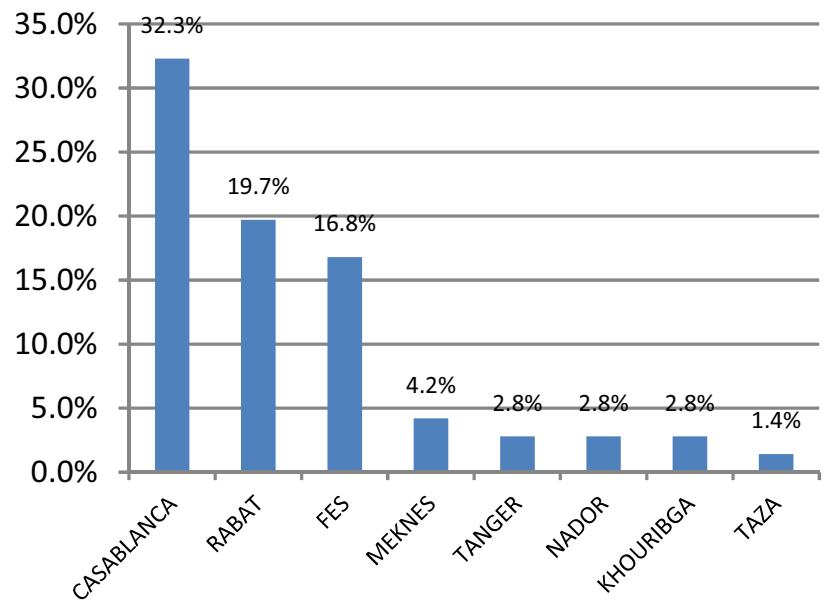

Fig. 7 Knowledge of the application of RTCM in Morocco

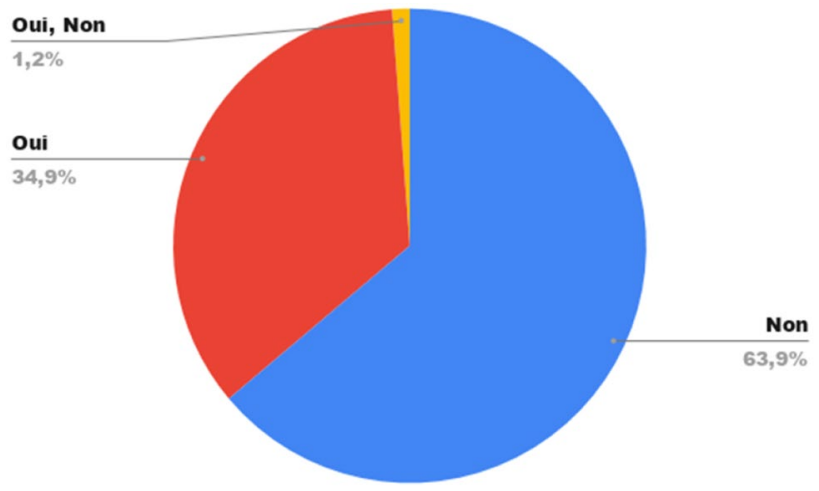

Fig. 8 Application rate of RTCM in Morocco

Fig. 6 Distribution of founded returns by city

In addition, the Casablanca region represents the most representative return, followed by Rabat and Fez, since these 3 cities represent the meeting point for specifiers and also, it is the segment which represents the massive number of constructions carried out.

On the other hand, on examining the results and as shown in the graph below (Fig. 7), we found that $73.5 \%$ of the speakers addressed already know that the RTCM has already been applied in Morocco since November 2015.

However, this percentage of knowledge of the provision of RTCM does not reflect its degree of application, since the results of the survey show that $63.9 \%$ of prescribers do not apply RTCM in their studies and constructions in comparison with $34.9 \%$ who apply it on a compulsory basis and $1.2 \%$ of the applicators on a voluntary basis, as shown in the graph below (Fig. 8);

According to the comments provided in the questionnaire, the main reason preventing them from applying the RTCM is the additional cost which will ultimately affect the consumer and since the competitors, not applying this regulation, present more price offers interesting.

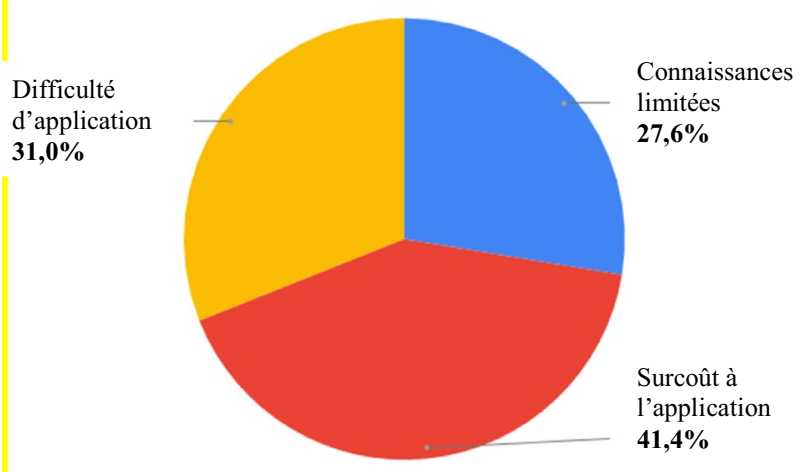

Fig. 9 The main obstacles to the application of the RTCM

Upon examination of the results represented in Fig. 9, it can be seen that $41.4 \%$ of the causes which hamper the application of the RTCM according to the prescribers interviewed are due to the additional cost of the application. For $31 \%$ of prescribers it is the difficulty of application which is the main cause, and they suggest simplifying the design process in accordance with the regulations. Finally, 


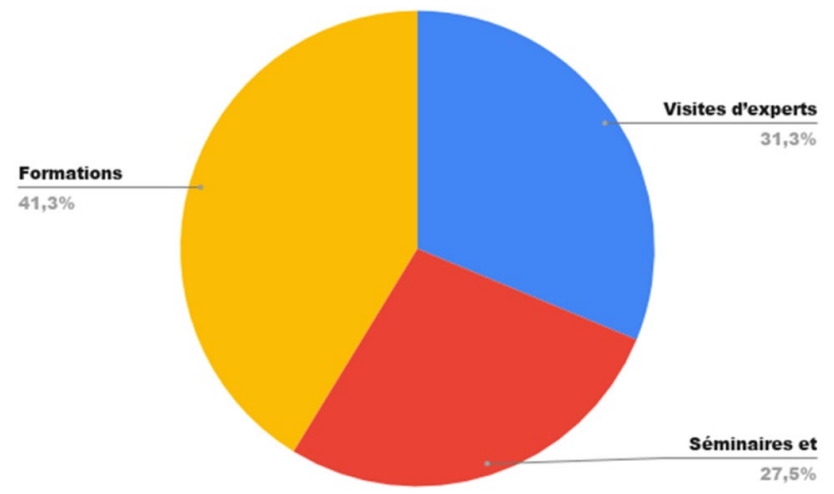

Fig. 10 Prescribers suggestions for in-depth knowledge of RTCM

for $27.6 \%$ of prescribers the obstacle is linked to limited knowledge of the mode of execution. The other causes mentioned in the comments collected are:

- The high cost of building materials to provide thermal insulation;

- A lack of sanctions mechanisms in the event of noncompliance with the RTCM;

- The procedure for obtaining the building permit is already quite slow and complex and the developers remain very reluctant with regard to this regulation... Added to this, the additional cost generated and the unfavorable tax provisions...

Nevertheless, we asked the prescribers via the same survey to provide us with their opinions to help popularize the RTCM facilitate its application and make it mandatory. The results of their suggestions are shown in Fig. 10 which shows that the training component occupies the majority percentage of $41.3 \%$, followed by $31.3 \%$ of the responses in favor of expert visits and awareness raising and finally $27.5 \%$ of opinions for communication via seminars and congresses.

The results of the survey also show that $67.1 \%$ of prescribers wish to have a compulsory application of the Thermal Construction Regulations (RTCM) against 32.9\% who wish that its application remains voluntary, (Fig. 11).

Among the remarks provided with the results of the survey, that concerning the objection to the application of the RTCM in a compulsory manner, since the majority of the speakers pretends that its application will have an impact on the sale price and a additional cost for the end customer.

In addition, the examination of the results of the investigation showed a predominance of the use of the standards relating to the thermal insulation of the buildings in the specifications of prescription and during the phase of the construction as the Fig. 12 shows it below:

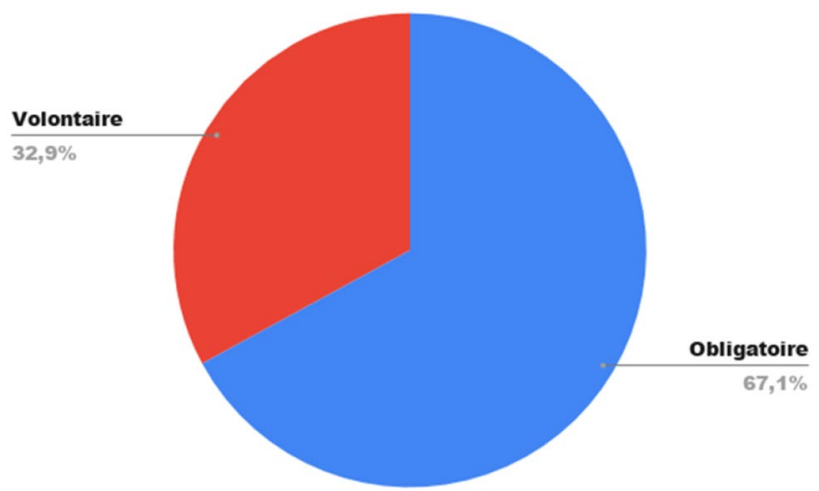

Fig. 11 Willingness to apply the RTCM: Mandatory or voluntary

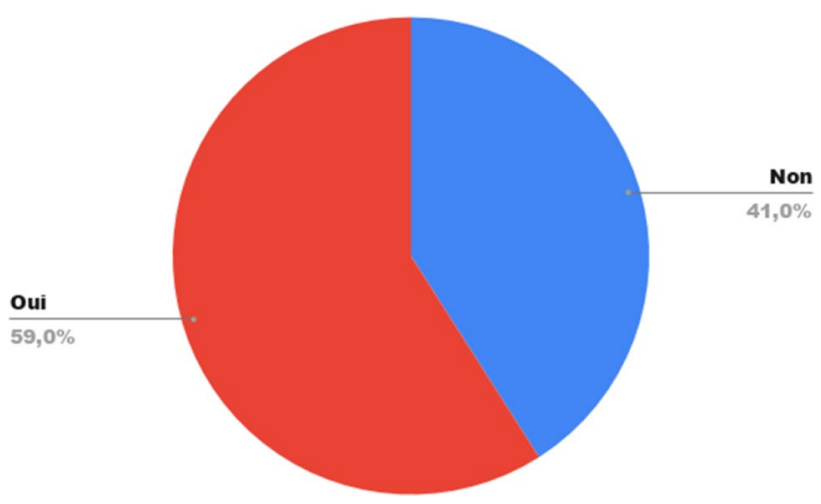

Fig. 12 Use of standards relating to the thermal insulation of buildings in specifications

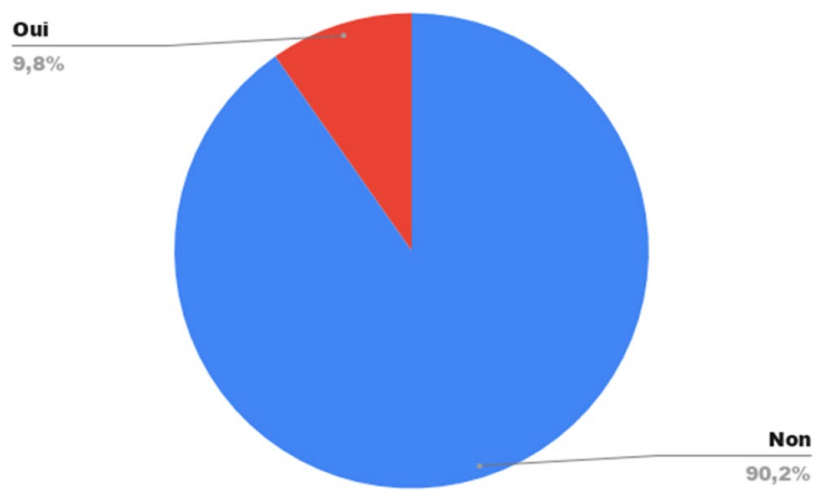

Fig. 13 Use of thermal simulation software in the study phase

In addition, the graph in Fig. 13 tells us about the degree of use of thermal simulation software, namely: TRNSYS, DESIGN BUILDER, IZUBA, VIRTUAL ENVIRONMENT SOFTWARE, $\ldots$ by architects, engineers and design offices in the phase of the realization of digital plans and thermal simulation of buildings. It turns out that $90.2 \%$ of those questioned do not use this software to make their studies 
a reality. On the other hand, the remaining $9.8 \%$ explained that their orientation will make it possible to better manage all these constraints in the same software regardless of current standards in this area.

This is the reason why, we questioned them if they wanted to take advantage of the existing on-board means for the integration of thermal simulation and the technical requirements of the RTCM in the practical side of the work tools and calculation software used. (Autocad, Archicad, Cype, Autodesk...) during the design and drawing phases of project plans to comply with standards and regulatory systems. In response as shown in Fig. 14, 82.5\% of prescribers encourage this approach.

In addition, among the motivations expressed by the prescribers during this survey to engage in this energyefficient orientation, we cite:

- Meet the requirements of energy efficiency since the cost of energy continues to increase;

- User well-being;

- The need to comply with regulations;

- Control of the construction process;

- Long-term energy comfort, environmental respect and sustainable development in general;

- Improvement of the technical performance and comfort of buildings while making savings on operating costs, and improving the actions of citizens in favor of the environment;

- Optimization of energy cost and better use of solar energy.

In addition, we also asked the respondents if they wanted to certify buildings applying the RTCM by existing energy efficiency labels in Morocco, namely BREAM, LEED, HQE... $80.5 \%$ of the responses affirmed their approval (Fig. 15).

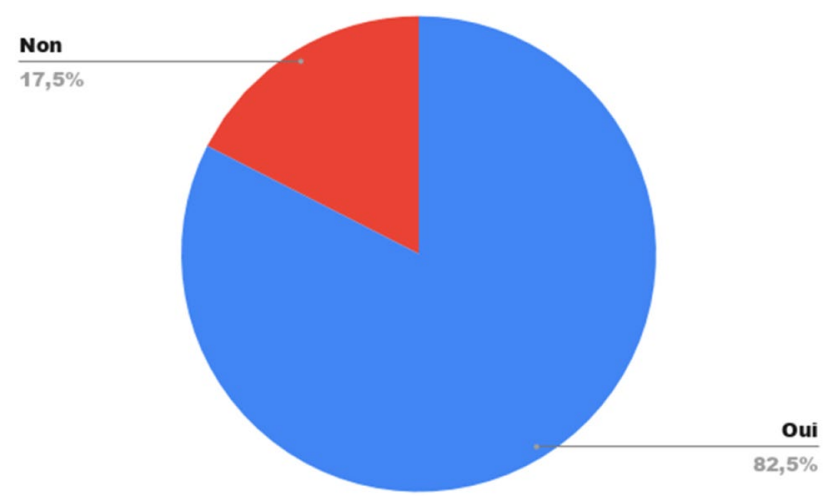

Fig. 14 Willingness to integrate regulatory systems into the working tools of prescribers

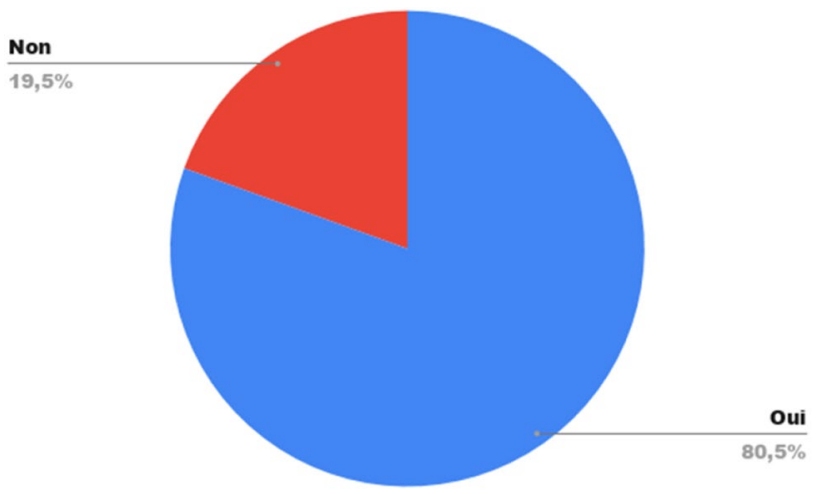

Fig. 15 Willingness to certify buildings with Eco-labels after the application of the RTCM

- General suggestions and remarks made by the respondents:

- Encourage the use of more efficient, innovative and above all inexpensive building materials and popularize them, because the construction industry, the mentality of promoters as well as consumers resists these products in Morocco;

- Reinforce the study by improving all aspects of comfort in housing in Morocco and not only the thermal component, namely the acoustic component, ventilation, hygiene (mold, humidity);

- Sensitize Architects, Engineers, Promoters, Citizens... on the RTCM, and require it for building authorization request files;

- Have a library of materials, standards, costs, products related to the subject in order to better facilitate studies of this kind;

- Adaptation of these regulations to the Moroccan context;

- Make these labels known to the territorial administration;

- Seize and inform the State departments, the territorial collectivities, the design offices on this subject and integrate this regulation in the schools of training of the technicians and engineers...;

- Review the RTCM so as to integrate all types of buildings including renovations, process thermal bridges in its Binayate software and also review all this software which remains very limited....;

- In order to generalize the application of the RTCM, the State should introduce incentive measures such as subsidies....;

- Controlling well the contributions after construction and checking the level of efficiency and its control over time by a periodic control system;

- Efficiency labels will have to take into account climate change as well as geographic location; 
- A popularization of RTCM is mandatory and the demonstration of direct gains in terms of cost related to its application;

- The market is not yet ready for the application of the RTCM from the point of view of construction materials, the culture of citizens and even for the cost compared to self-construction;

- Raise awareness and train all stakeholders, especially businesses;

- Limitation of certifying constructions just for the application of the RTCM, because the latter is only one pre-requisite among others and certification entails an additional cost that the promoters are not ready to pay at present;

- The RTCM has focused energy efficiency on insulation only, while other aspects are not yet addressed in this regulation;

- All stakeholders must think of a policy that does not hurt anyone and if there is a need for a real awareness campaign, it is with promoters that they should be carried out instead;

- It is necessary to require compliance with this regulation and to carry out checks as the Court of Auditors does for budgets;

- To apply this regulation we must change the way we urbanize our spaces;

- Certificates to be requested from the promoter at the time of the sale... (such as the technical inspection centers which are required by the state for the vehicle fleet).

\section{Perspective of the next work}

After the assembly of key data to identify the needs of decision makers in the construction sector from the survey sent, we then plan to integrate the requirements of the RTCM into their working tools allowing a better thermal simulation of the building, namely the choice of the sector, the choice of the climatic zone and its requirements in terms of technical data (TGBV bay window rate, $U$ of exposed roofs, $U$ of exterior walls,...) the standards to be required during construction, the choice of the most suitable construction materials for each zone according to their thermal conductivities, etc.

This research perspective will allow a practical application of the requirements of the RTCM and even a labeling of the building in the future.

\subsection{Example of the standards to be included in numerical simulation tools for thermally insulated buildings}

The Moroccan collection of standards published by the Moroccan Institute for Standardization (IMANOR) is around
15,000 standards that are constantly evolving, a large part of which is devoted to the thermal comfort of the building. We cite as an example the following standards [18]:

NM 19.7.003 2010 Thermal insulation products for buildings - Manufactured products of expanded polystyrene (EPS)-Specifications

NM EN 131642011 Thermal insulating products for buildings - Manufactured products from extruded polystyrene foam (XPS)-Specification

NM 19.7.005 2010 Thermal insulating products for buildings - Manufactured products made of rigid polyurethane foam (PUR)-Specifications

NM 19.7.006 2010 Thermal insulating products for buildings - Manufactured products made of phenolic foam (PF)-Specifications

NM 19.7.007 2010 Thermal insulating products for buildings - Manufactured cellular glass (CG) products-Specifications

NM 19.7.008 2010 Thermal insulating products for buildings - Manufactured products made of wood wool (WW)-Specifications

NM EN 131692012 Building thermal insulation products - Expanded perlite manufactured products (EPB)-Specifications.

\subsection{Insulating materials adapted to the RTCM}

The Thermal Construction Regulation in Morocco (RTCM) provides a pragmatic solution to the problem of excessive energy consumption in the building sector, whether residential or tertiary, and this mainly at the level of the passive component by using insulating materials known by a low thermal conductivity adapted to each climatic zone.

The integration of these insulating building materials will significantly reduce the need for air conditioning and heating. This reduction alone covers $50 \%$ of energy savings. Figure 16 is a study on the southern Mediterranean region over the period 2010-2030 which shows that we can gain $35 \%$ in heating and $14 \%$ in air conditioning [1] if we apply an efficient envelope and an appropriate thermal insulation to using insulating materials ensuring low thermal inertia. (Figure 17)

Good thermal insulation refers to good insulating material introduced into the building envelope to gain air conditioning and heating. Insulation materials are usually listed in four families. This classification is made according to their natures and origins [2]:

Examples of mineral insulators with their conductivity (W/m K):

- Glass wool: 0.03-0.045

- Rockwool: 0.032-0.04.

- Cellular glass: 0.035-0.048. 


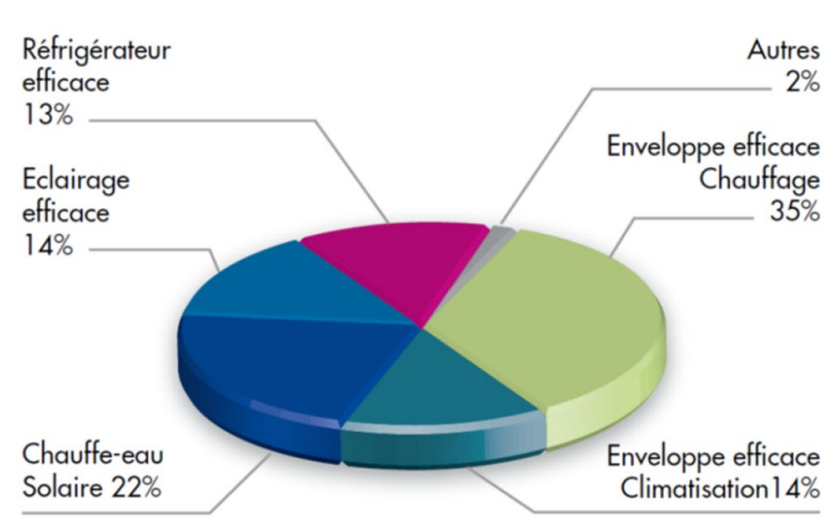

Fig. 16 Structure of energy efficiency potential in the southern Mediterranean region over the period 2010-2030 [1]

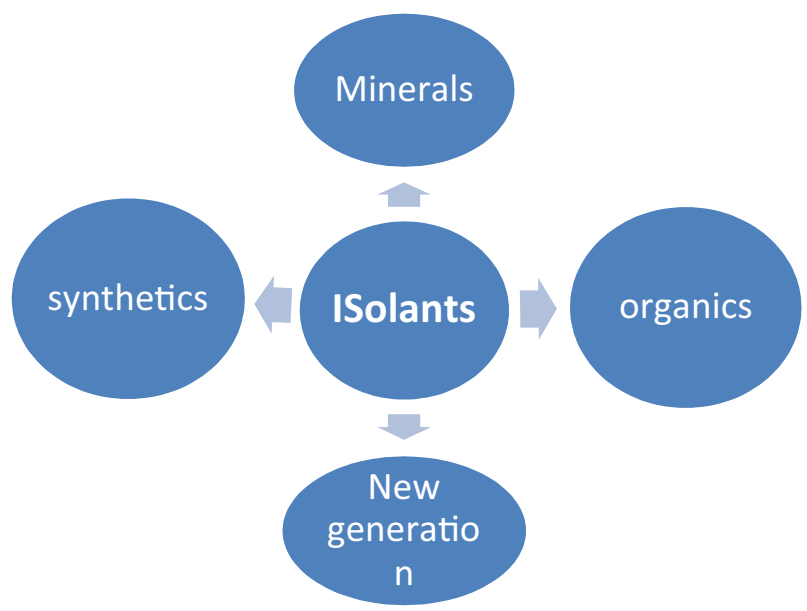

Fig. 17 Families of insulating materials

- Perlite: 0.045-0.06.

- Vermiculite: 0.045-0.08.

- Expanded clay: 0.09-0.16.

- Pozzolan: 0.1-0.2

Examples of organic insulators with their conductivity (W/m K):

- Cork: 0.032-0.045.

- Wood fiber: 0.037-0.049.

- Cotton wool: 0.037-0.042.

- Linen wool: 0.037-0.042.

- Cellulose wadding: 0.037-0.044.

- Hemp: 0.04-0.046.

- The coconut fiber: 0.037-0.050.

- The chenevotte: $0.048-0.06$.

- Sheep's wool: 0.035-0.042.

- Duck feather: 0.033-0.042.
Examples of synthetic insulators with their conductivity (W/m K):

- Expanded polystyrene: 0.029-0.035.

- Extruded polystyrene: 0.028-0.037.

- Polyurethane: 0.022-0.030.

- Phenolic foam: 0.018-0.035.

Examples of new generation insulators with their conductivity $(\mathrm{W} / \mathrm{m} \mathrm{K})$ :

- Airgel foam: 0.011 to 0.013 .

- Insulating panels: 0.0042 to 0.0050 .

Beyond the insulation materials whose main role in a construction is to improve the thermal performance of the walls, it was recently developed materials originally used to ensure the structure of the building, with improved thermal performance. This allows these building materials to also provide an insulation function. For example:

- Hemp brick: 0.048-0.06.

- Cellular concrete: 0.035 .

- Single-brick: 0.12 to 0.18 to 0.07 if the cells are filled with an insulator;

- Agglo monomur in pumice stone: 0.09-0.12.

- Foam concrete: 0.07-0.20.

In connection with this type of materials, several studies have been developed to study the possibility of substitution or incorporation of the results of this research into conventional building materials in order to have ecological and energy-efficient buildings.

In this context, the article by Rahim and all. 2017 [19] presented the results of the testing of a new concrete based on hemp and rapeseed, these materials have shown a certain response to the requirements of the RTCM given their low thermal conductivity which is around 0.12 and $0.09 \mathrm{~W} / \mathrm{mK}$ for hemp and rapeseed respectively.

And in Bourhaneddine Haba's thesis, 2017 [20], the author investigated the effect of adding date palm wood in concrete, the results showed that the dry thermal conductivity of date palm concrete is lower at $0.3 \mathrm{~W} \mathrm{~m}^{-1} \mathrm{~K}^{-1}$. However, despite the fact that this type of concrete has a low thermal conductivity, the problem of hygrometry "Rapid absorption of water" blocks their widened use until today, since this phenomenon influences the mechanical resistance of the final product.

On the other hand, the article by "Cinzia Buratti, Elisa Moretti, Elisa Belloni, Fabrizio Agosti" [21] studied the use of innovative insulation panels based on natural basalt fibers. 
After having measured the thermal conductivity of this type of panel, which is between 0.030 and $0.034 \mathrm{~W} / \mathrm{m} \mathrm{K}$. Compared with other traditional solutions such as rock wool or glass wool, this mineral material will be a good insulation solution that meets both the sanitary and mechanical requirements of the required construction products.

As well, the authors "F. Asdrubali, AL Pisello, F. D'Alessandro, F. Bianchi, M. Cornicchia, C. Fabiani" [22] developed in their article tests on the thermal and acoustic performances of the panels of corrugated cardboard commonly used in the packaging industry. The results show that this type of cardboard panels offers promising performance in terms of acoustic and thermal insulation capacity, slightly lower than the insulation panels commonly used. The test results showed that matching samples of C flute of 50 and $75 \mathrm{~mm}$ have a thermal conductivity of $0.053 \pm 0.001 \mathrm{~W} / \mathrm{mK}$ and matching samples of $E$ flute have slightly different $\lambda$, both within their limits. maximum permissible errors, namely $0.058 \pm 0.001$ and $0.060 \pm 0.001 \mathrm{~W} /$ $\mathrm{mK}$, respectively for 50 and $75 \mathrm{~mm}$.

\section{Conclusion}

This article first addresses the energy consumption that occupies the building sector at the global level, the southern Mediterranean region and Morocco. This majority energy consumption linked to the building sector calls for commitments made by several countries in order to find radical solutions to the problem of the high cost of energy bills linked mainly to air conditioning and heating, which alone occupy almost $50 \%$ of the building. overall energy consumption of the building.

Among the commitments made by several countries, we find the regulation of the building sector, more specifically the energy component. Morocco is also committed to this approach by setting up the Moroccan Construction Thermal Regulation (RTCM), in order to guarantee energy efficient buildings.

Despite the entry into force of the RTCM in November 2015 , its application is still voluntary. This led us to carry out a comparative study between the requirements of the thermal regulations of the two neighboring countries, characterized by a climatic approximation and whose regulations are both voluntary and compulsory simultaneously, namely Morocco and Tunisia.

From the input and output data of the comparisons made, it appears that Morocco is on the way to catching up with other countries that have implemented mandatory thermal building regulations. This delay is mainly due to a delay in the years of promulgation of the implementing regulatory texts.
In addition, and in order to consolidate our study, we carried out an online survey that we sent to decision-makers in the building sector in order to know, analyze and study their requirements and recommendations and to know the real cause that hinders the mandatory application. of the RTCM.

The perspective of the next work will consist above all in consolidating the suggestions proposed by the prescribers questioned. And this by:

First of all, the provision of the elements necessary to supply even more powerful work software for good thermal simulation, the approach of which will be developed in the next article. Or, by producing a guide in collaboration with IMANOR and AMEE encompassing the normative and regulatory devices to be taken into account in the study and design phases of buildings responding to the RTCM.

Then, by analyzing the actions that must be carried out by the state in terms of awareness, training in the field of energy-efficient construction, control and verification of compliance with the application of this regulation, promulgation of sanctioning regulatory texts, monitoring of the building permits filed and the data of the results of site inspections, the actions of subsidies to be set up, labeling, etc.

\section{Compliance with ethical standards}

Conflict of interest They have no conflict of interest.

\section{References}

1. Règlement Thermique de Construction au Maroc-Version simplifié par l'ADEREE

2. CETEMCO-Guide technique AZEL/Décembre 2018

3. Bouroubat K (2016) La construction durable: étude juridique comparative/Maroc-France. Droit. Université Paris-Saclay

4. https://fr.wikipedia.org/wiki/Consommation_\%C3\%A9ner g\%C3\%A9tique_des_b\%C3\%A2timents

5. Janda KB, Busch JF (1994) World wide status of energy standards for buildings. Energy 19(1):27-44

6. Yang L, Lam JC, Tsang CL (2008) Energy performance of building envelopes in different climate zones in China. Appl Energy 85:800

7. Saidur R (2009) Energy consumption, energy savings, and emission analysis in Malaysian office buildings. Energy Policy 37:4104-4113

8. Lombard LP, Jose $\mathrm{O}$, Christine $\mathrm{P}$ (2008) A review on buildings energy consumption information. Energy Build 40(3):394-398

9. Tso Geoffrey KF, Yau KK (2003) A study of domestic energy usage patterns in Hong Kong. Energy 28:1671-1682

10. Energy Information Administration (EIA), (2009a). World Energy Demand and Economic Outlook. http://www.eia.doe.gov/oiaf/ ieo/world./cited2009S

11. Birner S, Martinot E, (2002)The GEF energy-efficient product portfolio: emerging experience and lessons. Washington, DC 
12. OECD (Organisation for Economic Co-operation and Development) (2003) Environmentally Sustainable Buildings-Challenges and Policies. OECD, Paris

13. Iwaro Joseph, Mwasha Abraham (2010) A review of building energy regulation and policy for energy conservation in developing countries. Energy Policy 38:7744-7755

14. Moissan F (2005) Energy efficiency: a worldwide review. In: Proceedings of WEC COP 11, 6 December 2005

15. World Energy Council, 2010. Energy efficiency policies around the world: review and evaluation. http://www.worldenergy.org/ publications/energy_efficiency_policies_around_the_world/ cited2010S]

16. Allouhi A, El Fouih $Y$, Kousksou T, Jamil A, Zeraouli $Y$, Mourad $Y$ (2015) Energy consumption and efficiency in buildings: current status and future trends. J Cleaner Prod 109:118-130

17. http://www.cetiba.tn/

18. Catalogue IMANOR - Mars 2017/Guide de I'AMIB

19. Rahim M, Douzane O, Le Tran AD, Promis G, Langlet T (2017) Experimental investigation of hygrothermal behavior of two bio-based building envelopes. Energy Build 139:608-615

20. Bourhaneddine HABA (2017) Etude in situ des performances énergétiques et mécaniques des matériaux biosourcés et locaux. Université El-Hadj Lakhdar-BATNA 1, 2017
21. Buratti Cinzia, Moretti Elisa, Belloni Elisa, Agosti Fabrizio (2015) Thermal and acoustic performance evaluation of new basalt fiber insulation panels for buildings. Energy Procedia. 78:303-308

22. Asdrubali F, Pisello AL, D'Alessandro F, Bianchi F, Cornicchia M, Fabiani C (2015) Innovative cardboard based panels with recycled materials from the packaging industry: thermal and acoustic performance analysis. Energy Procedia. 78:321-326

23. Loi 47-09 relative à l'efficacité énergétique

24. La loi n²004-72

25. Tunisie: la réglementation thermique et énergétique des bâtiments neufs

26. www.muat.gov.ma

27. www.energymines.gov.tn

28. http://www.archibat.info/news.php?artid=74

29. www.amee.ma

Publisher's Note Springer Nature remains neutral with regard to jurisdictional claims in published maps and institutional affiliations. 